\title{
Desempenho, Digestibilidade e Características de Carcaça de Novilhos Zebuínos Alimentados com Dietas Contendo Diferentes Níveis de Concentrado ${ }^{1}$
}

\author{
Marcos Antonio Lana Costa ${ }^{2}$, Sebastião de Campos Valadares Filho ${ }^{3}$, Mário Fonseca Paulino ${ }^{3}$, \\ Rilene Ferreira Diniz Valadares ${ }^{4}$, Paulo Roberto Cecon ${ }^{5}$, Pedro Veiga Rodrigues Paulino ${ }^{6}$, Eduardo \\ Henrique Bevitori Kling de Moraes ${ }^{7}$, Karla Alves Magalhães ${ }^{7}$
}

\begin{abstract}
RESUMO - O estudo foi desenvolvido com o objetivo de avaliar os consumos e as digestibilidades dos nutrientes; o teor de nutrientes digestíveis totais (NDT) das rações; a conversão alimentar (CA); os ganhos médios diários de peso vivo (GMDPV), de peso de corpo vazio (GMDPVZ) e de carcaça (GMDCAR); os rendimentos de carcaça e dos cortes primários da carcaça; o comprimento da carcaça (CCAR); a área de olho de lombo (AOL) e a espessura de gordura subcutânea (EG) de novilhos anelorados, com peso vivo médio inicial de $270 \mathrm{~kg}$, alimentados com dietas contendo 5, 35 e 65\% de concentrado, em regime de confinamento. Os consumos de matéria seca e matéria orgânica foram afetados de forma quadrática pelo incremento de concentrado na dieta. Os consumos de extrato etéreo e carboidratos não-fibrosos aumentaram e o de fibra em detergente neutro decresceu linearmente em função do aumento de concentrado. O consumo de proteína bruta não foi afetado pelo nível de concentrado da dieta. Os teores de NDT e as digestibilidades da matéria seca, matéria orgânica, extrato etéreo e carboidratos não-fibrosos aumentaram e a digestibilidade da fibra em detergente neutro diminuiu linearmente com o aumento nos níveis de concentrado das dietas. A digestibilidade da proteína bruta (DPB) não foi alterada quando a silagem pré-seca de capim-braquiária foi utilizada como volumoso. Entretanto, a DPB aumentou linearmente quando a silagem pré-seca de capim-tifton foi utilizada na alimentação dos animais. A CA reduziu, enquanto os GMDPV, GMDPVZ, GMDCAR, a AOL e a EG elevaram linearmente com o acréscimo de concentrado na dieta. O CCAR e rendimentos de carcaça e dos cortes primários da carcaça, com exceção do rendimento de coxão, não foram afetados pela inclusão de concentrado nas dietas. A inclusão de concentrado nas dietas promoveu melhor digestibilidade e melhor desempenho aos animais.
\end{abstract}

Palavras-chave: carne, confinamento, ganho de peso, gado de corte

\section{Productive Performance, Digestibility and Carcass Characteristics of Zebu Steers Fed Diets with Different Concentrate Levels}

\begin{abstract}
This research was developed to evaluate the intake and digestibility of nutrients; feed/gain conversion (FC); average daily live weight (LWG), empty body weight (EBWG) and carcass (CG) gains; the carcass dressing percentage and the basic cuts percentage; the carcass length (CL); the loin eye area (LEA) and the subcutaneous fat thickness (SFT) of Zebu steers, with initial average live weigth of $270 \mathrm{~kg}$, fed with 5, 35 e $65 \%$ of concentrate, in feedlot. The dry matter and organic matter intake were quadractily influenced by the increasing levels of concentrate in the diet. The ether extract and nonfiber carbohydrate intakes increased and the neutral detergent fiber intake decreased linearly as the concentrate level increased. The crude protein intake was not affected by the concentrate level. The TDN level and digestibility of the dry matter, organic matter, ether extract and non-fiber carbohydrate increased and the neutral detergent fiber digestibility decreased linearly as concentrate level in the ration incresead. The digestibility of the $\mathrm{CP}$ was not affected, when Brachiaria brizantha haylage was used as roughage. However, the digestibility of the CP increased linearly, when the Cynodon dactylon was used in the feeding of the animals. The FC decreased and the LWG, EBWG, CG, LEA and SFT increased linearly as the concentrate levels in the diets increased. The CL, the carcass dressing percentage and the basic cuts percentage, excluding leg percentage, were not affected by the concentrate levels in the diet. The inclusion of concentrate in the diets increased the digestibility and improved the productive performance of the animals.
\end{abstract}

Key Words: meat, feedlot, weight gain, beef cattle

\footnotetext{
${ }_{1}$ Parte da tese de Mestrado do primeiro autor, parcialmente financiada pela FAPEMIG

2 Zootecnista, M.Sc. E.mail: mzootec@yahoo.com.br

3 Professor do DZO/UFV. E.mail: scvfilho@ufv.br

${ }^{4}$ Professora do DVT/UFV.

5 Professor DPI/UFV.

${ }^{6}$ Aluno do curso de Doutrorado, DZO/UFV

${ }^{7}$ Aluno do curso de Mestrado, DZO/UFV.
} 


\section{Introdução}

A busca pela melhoria da eficiência na produção de carne tem mudado o perfil da pecuária brasileira, que da posição de empreendimento extrativista tem atingido diferentes patamares no sentido de intensificação total. Neste contexto, a suplementação a pasto e o confinamento surgem como alternativas capazes de reduzir a idade de abate, otimizar a taxa de desfrute dos rebanhos, aumentar o giro de capital e produzir carcaças de alta qualidade, aspectos que caracterizam uma pecuária evoluída.

Como a alimentação é responsável por grande parte dos custos de produção nos sistemas de confinamento, a condução criteriosa dos programas de alimentação exige o respaldo de estudos que busquem conhecer, com maior precisão, as interações e os impactos produzidos pelo emprego do concentrado na alimentação de bovinos. Além disso, ainda que vários resultados experimentais mostrem que o ganho de peso diário é maior, quando se utilizam rações com maior porcentagem de concentrado, a resposta animal a adição de concentrado, segundo Gesualdi Júnior et al. (2000a), tende a ser curvilínea. Portanto, o estudo de diferentes proporções de concentrado nas rações é fundamental, pois permite determinar seu nível ótimo, para que se obtenha o melhor desempenho animal aliado à melhor resposta econômica.

De acordo com Mertens (1994), o desempenho animal é função direta do consumo de matéria seca digestível. Neste contexto, 60 a 90\% do desempenho decorrem de variação do consumo, enquanto 10 a $40 \%$ advêm de flutuações na digestibilidade. Portanto, o consumo é considerado o fator mais importante na determinação do desempenho animal.

As teorias que explicam o controle do consumo voluntário nos ruminantes admitem que este mecanismo é produto da ação integrada ou isolada de fatores físicos, químicos e fisiológicos. A demanda energética do animal define o consumo de dietas de alta densidade calórica, ao passo que a capacidade física do trato gastrintestinal determina o consumo de dietas de baixas qualidade e densidade energética (Van Soest, 1994). Entretanto, segundo Mertens (1994), além de fatores físicos e fisiológicos responsáveis pela modulação do consumo, existe também o fator psicogênico, que envolve a resposta comportamental do animal, frente a fatores inibidores ou estimuladores no alimento ou no manejo alimen- tar, que não estariam relacionados ao valor energético do alimento nem ao efeito do enchimento.

Além do conhecimento do consumo e da composição bromatológica dos alimentos, torna-se importante o conhecimento da utilização dos nutrientes pelo animal, que é obtido por meio de estudos de digestão. Segundo Coelho da Silva \& Leão (1979), digestibilidade é característica do alimento e indica a porcentagem de cada nutriente de um alimento que o animal pode utilizar. Deve-se reconhecer, no entanto, que fatores ligados ao animal, ao manejo da alimentação e ao ambiente podem afetar a digestibilidade de determinado alimento. De modo geral, o aumento na proporção de concentrado na ração leva à melhoria em sua digestibilidade.

Dentro da concepção de produção de carne bovina, que começa a se estabelecer no setor agroindustrial da carne no Brasil, qualidade de carne, rendimento e composição de carcaça passam a ser elementos importantes e necessários para colocar o país como competidor em um mercado crescente e cada vez mais exigente.

O confinamento é uma ferramenta que possibilita o abate de animais jovens e bem acabados, proporcionando, em geral, carcaças e carne de melhor qualidade. Considerando-se que, no Brasil, ainda não se pratica a adequada remuneração pela qualidade das carcaças e da carne e que o concentrado, pelo seu conteúdo energético, seja responsável pela engorda dos animais e também um dos itens mais onerosos nos custos operacionais de um confinamento, a determinação de um nível ótimo de concentrado, que proporcione carcaça com acabamento mínimo, é uma maneira de o produtor conseguir maior lucratividade no confinamento (Feijó et al., 1996).

O componente de maior importância na carcaça é o músculo, uma vez que este constitui a carne magra, comestível e disponível para venda. A gordura é uma fração importante, pois influencia no aspecto visual da carcaça, na porção comestível e na qualidade da carne, além de servir como proteção (gordura subcutânea) contra a desidratação no resfriamento das carcaças (Moletta \& Restle, 1996). Atualmente, busca-se carcaças com elevada proporção de músculos e com quantidade mínima de gordura que garanta a suculência e o sabor ótimo da carne, além de cobertura adiposa suficiente para evitar a desidratação e o escurecimento da carne frigorificada (Luchiari Filho, 2000). 
Com o objetivo de avaliar o desempenho produtivo, a digestibilidade e características da carcaça de novilhos anelorados, submetidos a diferentes níveis de concentrado na dieta, foi desenvolvido este trabalho.

\section{Material e Métodos}

O experimento foi conduzido no Departamento de Zootecnia do Centro de Ciências Agrárias da Universidade Federal de Viçosa, em Viçosa-MG, utilizando-se 16 bovinos anelorados, castrados, com peso vivo médio inicial de $270 \mathrm{~kg}$ e aproximadamente 24 meses de idade, confinados em baias individuais. Inicialmente, os animais foram pesados, identificados e vermifugados. Após o período de adaptação (14 dias), quatro animais foram abatidos, servindo de referência para estimativa do ganho médio diário de peso de corpo vazio. Os animais remanescentes foram distribuídos em três tratamentos, com três diferentes níveis de concentrado nas dietas (5; 35 e 65\%), em delineamento inteiramente casualizado, com quatro repetições por tratamento.

As rações foram formuladas de modo a serem isoprotéicas. O volumoso utilizado foi constituído de silagem pré-seca de capim-braquiária (Brachiaria brizantha), fornecido durante os primeiros 72 dias do experimento. Em razão da impossibilidade de obtenção do mesmo alimento, foi substituído pela silagem pré-seca de capim-tifton (Cynodon dactylon) no período final do experimento (37 dias).

As dietas foram fornecidas à vontade, uma vez ao dia, e ajustadas de forma a manter as sobras de 5 a $10 \%$ do oferecido. A quantidade de alimento oferecido foi registrada diariamente e, semanalmente, foram coletadas amostras dos concentrados, por tratamento, e das sobras, por animal. O volumoso foi amostrado diariamente e, ao final de cada período de 28 dias, foi feita uma amostra composta. As amostras semanais de concentrado e de sobras foram agrupadas, de forma proporcional, em cada período de 28 dias, constituindo-se amostras compostas, que foram présecas em estufa de ventilação forçada a $65^{\circ} \mathrm{C}$ e processadas em moinho com peneira de malha de $1 \mathrm{~mm}$, para posteriores análises laboratoriais, adotando-se o mesmo procedimento para as amostras compostas do volumoso. A descrição dos ingredientes utilizados na formulação dos concentrados encontra-se na Tabela 1. A composição bromatológica média dos concentrados e do volumoso é apresentada na Tabela 2 e a composição média das dietas, na Tabela 3.

As determinações de matéria seca (MS), matéria orgânica (MO), nitrogênio total, extrato etéreo (EE), fibra em detergente neutro (FDN), fibra em detergente ácido (FDA) e lignina foram realizadas segundo Silva \& Queiroz (2002), sendo a proteína bruta (PB) obtida pelo produto entre o teor de nitrogênio total e

\begin{tabular}{|c|c|c|c|}
\hline \multirow[t]{2}{*}{$\begin{array}{l}\text { Ingredientes (\% MN) } \\
\text { Ingredients (\% NM) }\end{array}$} & \multicolumn{3}{|c|}{$\begin{array}{c}\text { Níveis de concentrado na dieta (\%) } \\
\text { Dietary concentrate levels }(\%)\end{array}$} \\
\hline & 5 & 35 & 65 \\
\hline $\begin{array}{l}\text { Farelo de trigo } \\
\text { Wheat bran }\end{array}$ & - & 50,00 & 50,00 \\
\hline Fubá de milho & - & 26,30 & 40,80 \\
\hline $\begin{array}{l}\text { Farelo de soja } \\
\text { Soybean meal }\end{array}$ & 70,08 & 21,90 & 7,40 \\
\hline $\begin{array}{l}\text { Uréia } \\
\text { Urea }\end{array}$ & 18,00 & - & - \\
\hline $\begin{array}{l}\text { Sulfato de amônio } \\
\text { Amonnium sulfate }\end{array}$ & 2,00 & - & - \\
\hline $\begin{array}{l}\text { Calcário calcítico } \\
\text { Calcium carbonate }\end{array}$ & 1,30 & 1,10 & 1,40 \\
\hline $\begin{array}{l}\text { Fosfato bicálcico } \\
\text { Dicalcium phosphate }\end{array}$ & 3,90 & - & - \\
\hline $\begin{array}{l}\text { Cloreto de sódio } \\
\text { Sodium chloride }\end{array}$ & 4,40 & 0,65 & 0,37 \\
\hline $\begin{array}{l}\text { Premix mineral } \\
\text { Mineral mixture }\end{array}$ & 0,32 & 0,05 & 0,03 \\
\hline
\end{tabular}


Tabela 2 - Teores médios de matéria seca (MS), matéria orgânica (MO), proteína bruta (PB), compostos nitrogenados insolúveis em detergente neutro (NIDN), compostos nitrogenados insolúveis em detergente ácido (NIDA), extrato etéreo (EE), fibra em detergente neutro (FDN), fibra em detergente neutro corrigida para cinzas e proteína (FDNcp), carboidratos não-fibrosos (CNF), fibra em detergente ácido (FDA) e lignina dos concentrados experimentais e do volumoso

Table 2 - Average contents of dry matter (DM), organic matter (OM), crude protein (CP), neutral detergent insoluble nitrogen (NDIN), acid detergent insoluble nitrogen (ADIN), ether extract $(E E)$, neutral detergent fiber (NDF), neutral detergent fiber adjusted for ash and protein (NDF $\left.{ }_{a p}\right)$, nonfiber carbohydrate (NFC), acid detergent fiber (ADF) and lignin of concentrates and roughage

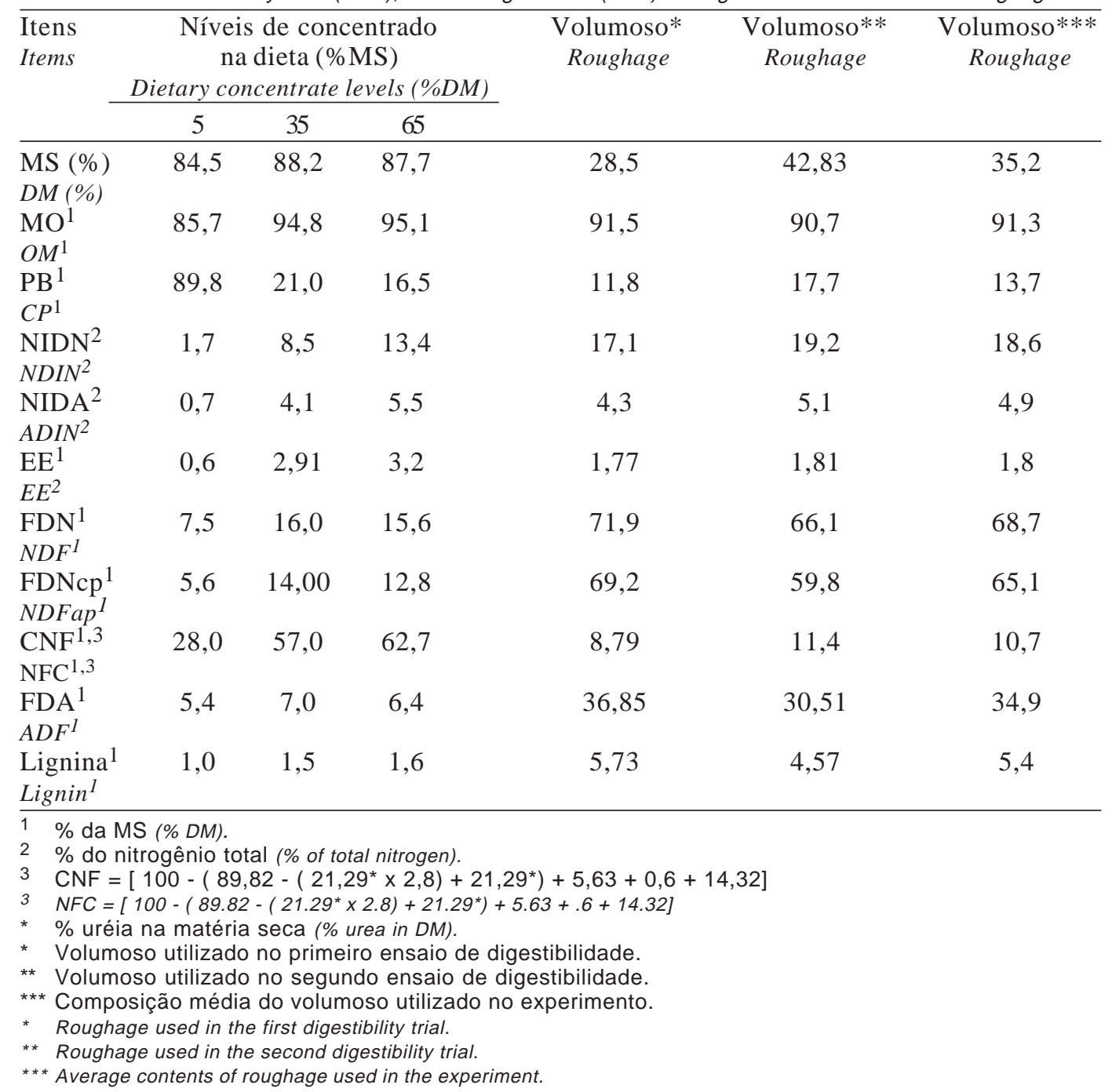

o fator 6,25. Os carboidrados não-fibrosos (CNF) foram calculados de acordo com Weiss (1999), como: $\mathrm{CNF}(\%)=100-(\% \mathrm{FDNcp}+\% \mathrm{~PB}+\% \mathrm{EE}+\%$ cinzas $)$. Para o concentrado referente ao tratamento com $5 \%$, em virtude da presença de uréia em sua constituição, o teor de CNF foi estimado como proposto por Hall (2000): $\mathrm{CNF}=100-((\% \mathrm{~PB}-\% \mathrm{~PB}$ derivado da uréia + peso $\%$ da uréia) $+\% \mathrm{FDNcp}+\% \mathrm{EE}+\%$ cinzas).

Os teores de nutrientes digestíveis totais (NDT) foram obtidos a partir da seguinte equação somativa: $\mathrm{NDT}=\mathrm{PBD}+2,25 \mathrm{x}$ EED + CNFD + FDNcpD, de modo que PBD, EED, CNFD e FDNcpD significam, respectivamente, proteína bruta digestível, extrato etéreo digestível, carboidratos não-fibrosos digestíveis e fibra em detergente neutro (isenta de cinzas e proteína) digestível. Para determinação das digestibilidades aparentes da MS, MO, PB, EE, FDN e CNF, foi realizado um ensaio de digestibilidade aos 50 dias de experimento, utilizando-se todos os animais. O período de coleta teve duração de sete dias, durante os quais se procederam amostragens dos alimentos consumidos, das sobras e fezes, para posteriores análises.

As fezes foram coletadas diretamente no piso, imediatamente após a defecação, em dois períodos 
Tabela 3 - Teores médios de matéria orgânica (MO), proteína bruta (PB), extrato etéreo (EE), fibra em detergente neutro (FDN), fibra em detergente neutro corrigida para cinza e proteína (FDNcp), carboidratos não-fibrosos (CNF), fibra em detergente ácido (FDA), lignina e nutrientes digestíveis totais (NDT) das dietas experimentais contendo diferentes níveis de concentrado

Table 3 - Aerage contents of dry matter (DM), organic matter (OM), crude protein $(C P)$, ether extract $(E E)$, neutral detergent fiber (NDF), neutral detergent fiber adjusted for ash an protein $\left(N D F_{a p}\right)$, nonfiber carbohydrates (NFC), acid detergent fiber (ADF), lignin and total digestible nutrients of diets with different concentrate levels

\begin{tabular}{|c|c|c|c|}
\hline \multirow[t]{2}{*}{$\begin{array}{l}\text { Itens } \\
\text { Items }\end{array}$} & \multicolumn{3}{|c|}{$\begin{array}{l}\text { Níveis de concentrado }(\% \mathrm{MS}) \\
\text { Dietary concentrate levels }(\% D M)\end{array}$} \\
\hline & 5 & 35 & 65 \\
\hline $\mathrm{MO}^{1}$ & 91,0 & 92,5 & 93,8 \\
\hline $\begin{array}{l}\mathrm{OM}^{1} \\
\mathrm{~PB}^{1}\end{array}$ & 17,4 & 16,3 & 15,5 \\
\hline $\begin{array}{l}C P^{1} \\
\mathrm{EE}^{1}\end{array}$ & 1,7 & 2,2 & 2,7 \\
\hline $\begin{array}{l}E E^{1} \\
\mathrm{FDN}^{1} \\
N D F^{1}\end{array}$ & 65,7 & 49,9 & 33,9 \\
\hline $\begin{array}{l}\text { FDNcp } \\
N D F^{1}\end{array}$ & 62,1 & 46,8 & 30,8 \\
\hline $\begin{array}{l}N D F_{C P 1} \\
\mathrm{CNF}^{1} \\
F C N^{1}\end{array}$ & 11,6 & 27,3 & 44,8 \\
\hline $\begin{array}{l}\mathrm{FDA}^{1} \\
A D F^{1}\end{array}$ & 33,5 & 24,9 & 16,3 \\
\hline $\begin{array}{l}\text { Lignina }^{1} \\
\text { Lignin }^{1}\end{array}$ & 5,2 & 4,0 & 2,9 \\
\hline $\begin{array}{l}\text { NDT estimado }{ }^{1 *} \\
\text { TDN }_{\text {estimated }}{ }^{*}\end{array}$ & 65,6 & 69,6 & 74,3 \\
\hline
\end{tabular}

(manhã e tarde), no segundo e no quinto dia do período de coleta. As amostras de fezes foram homogeneizadas, acondicionadas em pratos de alumínio e pré-secas em estufa de ventilação forçada, a $65^{\circ} \mathrm{C}$, durante 72 horas. Em seguida, foram processadas em moinho com peneira de malha de $1 \mathrm{~mm}$ e agrupadas de forma proporcional, constituindo-se amostras compostas de cada animal.

Empregou-se o indicador interno fibra em detergente ácido indigestível (FDAi) para se estimar a produção de matéria seca fecal, conforme proposto por Cochran et al. (1986), entretanto, utilizou-se incubação ruminal em sacos de ankom, por 144 horas, em vez da digestibilidade in vitro sugerida pelo autor.

Em virtude da mudança na caracterização do volumoso, outro ensaio de digestibilidade foi realizado ao $91^{\mathrm{o}}$ dia experimental, adotando-se os mesmos procedimentos.

Os animais foram pesados ao início do experimento e, posteriormente, a cada 28 dias, para avaliação do ganho médio diário de peso vivo (GMDPV).
As pesagens foram sempre precedidas por jejum alimentar de 16 horas. O abate foi efetuado de forma escalonada, com os animais dos tratamentos com 5 , 35 e $65 \%$ de concentrado nas dietas, abatidos, respectivamente, após 109, 104 e 102 dias de confinamento. Outros detalhes da metodologia foram descritos nos trabalhos de Paulino et al.( 2004a,b,c).

Após o abate, o aparelho gastrintestinal de cada animal foi esvaziado e, juntamente com os órgãos, foram lavados, pesados e somados às demais partes do corpo (carcaça, cabeça, couro, cauda, pés e sangue), para determinação do peso de corpo vazio (PCVZ). A relação entre o PCVZ e o peso vivo (PV) dos animais referência abatidos no início do experimento foi utilizada para estimativa do PCVZ inicial dos animais, podendo-se então avaliar o ganho médio diário de peso de corpo vazio (GMDPVZ).

A carcaça de cada animal foi dividida ao meio e, em seguida, resfriada em câmara fria durante 18 horas a $-5^{\circ} \mathrm{C}$. Decorrido esse tempo, realizou-se a pesagem da carcaça a frio, para obtenção de seu rendimento em 
relação ao peso vivo (RCPV) e ao peso de corpo vazio (RCPVZ). Também foi medido o comprimento da carcaça direita e determinou-se, posteriormente, o rendimento dos cortes básicos. Os rendimentos dos cortes básicos foram determinados em relação ao peso da carcaça. O corte dianteiro foi separado do traseiro entre a quinta e a sexta costelas; o dianteiro compreendeu o acém e a paleta completa, enquanto o traseiro completo compreendeu a ponta de agulha, o coxão e a alcatra completa. Na meia-carcaça esquerda, foram medidas a área de olho do músculo Longissimus dorsi (área de olho de lombo), à altura da $12^{\circ}$ costela, e a espessura da gordura subcutânea.

Os resultados foram interpretados estatisticamente por meio de análises de variância e regressão, utilizando-se o Sistema de Análises Estatísticas e Genéticas - SAEG (UFV, 1997). Os critérios adotados para escolha do modelo foram o coeficiente de determina- ção, calculado como a relação entre a soma de quadrados da regressão e a soma de quadrados de tratamentos, e a significância observada dos coeficientes de regressão, por meio do teste $\mathrm{F}$, a $5 \%$ de probabilidade.

Esse experimento faz parte de um trabalho de exigências nutricionais descrito por Paulino et al. (2004 a, b, c).

\section{Resultados e Discussão}

As médias, os coeficientes de variação e de determinação e as equações de regressão referentes aos consumos de matéria seca (CMS), matéria orgânica $(\mathrm{CMO})$, proteína bruta $(\mathrm{CPB})$, extrato etéreo $(\mathrm{CEE})$, fibra em detergente neutro (CFDN) e carboidratos não-fibrosos (CCNF) e a conversão alimentar (CA), em função dos níveis de concentrado nas dietas (C),

Tabela 4 - Médias, coeficientes de variação (CV) e de determinação $\left(r^{2} / R^{2}\right)$ e equações de regressão (ER) para os consumos de matéria seca (CMS), matéria orgânica (CMO), proteína bruta (CPB), extrato etéreo (CEE), fibra em detergente neutro (CFDN) e carboidratos não-fibrosos (CCNF) e a conversão alimentar (CA), em função dos níveis de concentrado nas dietas $(C)$

Table 4 - Means, coefficients of variation (CV) and determination $\left(r^{2}\right)$ and fitted regression equations $(R E)$ for intakes of dry matter (DMI), organic matter (OMI), crude protein (CPI), ether extract (EEI), neutral detergent fiber (NDFI) and nonfiber carbohydrate (NFCI) and feed/gain ratio (FC), according to different concentrate levels (C) in the diets

\begin{tabular}{|c|c|c|c|c|c|c|}
\hline \multirow[t]{2}{*}{$\begin{array}{l}\text { Itens } \\
\text { Items }\end{array}$} & \multicolumn{3}{|c|}{$\begin{array}{c}\text { Níveis de concentrado } \\
\text { na dieta }(\% \mathrm{MS}) \\
\text { Dietary concentrate } \\
\text { levels }(\% \text { DM) } \\
\end{array}$} & \multirow[t]{2}{*}{$\mathrm{CV}(\%)$} & \multirow[t]{2}{*}{$\left(\mathrm{r}^{2} / \mathrm{R}^{2}\right)$} & \multirow[t]{2}{*}{$\mathrm{ER}(\mathrm{p}<0,05)$} \\
\hline & 5 & 35 & 65 & & & \\
\hline $\begin{array}{l}\text { CMS (kg/dia) } \\
\text { DMI (kg/dia) }\end{array}$ & 6,6 & 8,1 & 7,8 & 11,8 & 100 & 1 \\
\hline $\begin{array}{l}\text { CMS (\%PV) } \\
D M I(\% P V)\end{array}$ & 2,1 & 2,5 & 2,5 & 15,0 & 100 & 2 \\
\hline $\begin{array}{l}\text { CMO (kg/dia) } \\
O M I(k g / d i a)\end{array}$ & 6,0 & 7,5 & 7,3 & 12,0 & 100 & 3 \\
\hline $\begin{array}{l}\text { CPB }(\mathrm{kg} / \mathrm{dia}) \\
\text { CPI }(\mathrm{kg} / \text { dia })\end{array}$ & 1,2 & 1,3 & 1,2 & 11,2 & - & $\hat{Y}=1,23$ \\
\hline $\begin{array}{l}\text { CEE (kg/dia }) \\
E E I(k g / d i a)\end{array}$ & 0,1 & 0,2 & 0,2 & 13,7 & 99,04 & $\hat{Y}=0,111875+0,0017083 \mathrm{C}$ \\
\hline $\begin{array}{l}\text { CFDN (kg/dia) } \\
N D F I(k g / d i a)\end{array}$ & 4,3 & 4,0 & 2,8 & 10,1 & 89,12 & $\hat{Y}=4,63396-0,026375 \mathrm{C}$ \\
\hline $\begin{array}{l}\text { CFDN (\%PV) } \\
N D F I(\% P V)\end{array}$ & 1,4 & 1,2 & 0,8 & 5,7 & 95,13 & $\hat{\mathrm{Y}}=1,49187-0,00945833 \mathrm{C}$ \\
\hline $\begin{array}{l}\text { CCNF (kg/dia) } \\
N F C I(k g / d i a)\end{array}$ & 0,5 & 1,9 & 3,1 & 16,8 & 99,99 & $\hat{Y}=0,316042+0,0435417 \mathrm{C}$ \\
\hline $\begin{array}{l}\mathrm{CA}(\mathrm{kgMS} / \mathrm{kgPV}) \\
F C(k g M S / k g P V)\end{array}$ & 10,4 & 9,0 & 7,6 & 20,8 & 99,99 & $\hat{Y}=10,6756-0,047569 \mathrm{C}$ \\
\hline
\end{tabular}


são apresentados na Tabela 4. O CMS, expresso em $\mathrm{kg} /$ dia e em \% do PV, e o CMO (kg/dia) apresentaram efeito quadrático em função dos níveis de concentrado, sendo os consumos máximos estimados de 8,$2 ; 2,5$ e 7,6, observados com 45,6; 47,6 e 47,4\% de concentrado, respectivamente.

Da mesma forma, Véras et al. (2000a) e Ítavo et al. (2002) também encontraram efeito quadrático para o CMS, expresso em kg/dia, quando estudaram diferentes níveis de concentrado na dieta. Os consumos máximos foram estimados para os níveis de 55 e $45,9 \%$ de concentrado. Por outro lado, Dias et al. (2000) e Souza et al. (2002) reportaram repostas lineares crescentes para o CMS, enquanto Strack et al. (2001) não encontraram aumento no consumo de MS, em função dos níveis de concentrado. A divergência de resultados entre os trabalhos permite inferir que o consumo de MS é uma variável complexa, que pode ser afetada por diversos fatores, relativos ao animal, ao alimento, à alimentação e às condições climáticas, que interagem e passam a ser determinantes.

Os CEE e CCNF elevaram linearmente em função da adição de concentrado nas dietas. Comportamento inverso foi verificado para o CFDN, que diminuiu linearmente, em ambas as formas de expressão $(\mathrm{kg} /$ dia e \%PV), com o incremento no nível de concentrado na dieta. O efeito linear no CFDN pode ser atribuído à diminuição substancial nos níveis deste nutriente na dieta, em função do acréscimo de concentrado nas rações.

Por outro lado, o CPB não foi afetado, apresentando média de $1,23 \mathrm{~kg} / \mathrm{dia}$, o que pode ser explicado pelo fato de que, mesmo calculadas de forma a serem isoprotéicas, em função da variação nas características do volumoso, as dietas apresentaram pequena redução nos teores de PB com a adição de concentrado. Desse modo, o aumento no CMS, em função da adição de concentrado na dieta, não refletiu aumento no consumo de $\mathrm{PB}$.

A CA decresceu linearmente com o aumento no teor de concentrado na ração, estando de acordo com Euclides Filho et al. (1997), que afirmaram que o aumento no nível de concentrado melhora a conversão alimentar. Maior densidade energética resulta em maior ingestão de energia e, portanto, menos alimento é requerido para o ganho de peso, resultando em melhor conversão alimentar.

Em função da mudança de volumoso durante o período experimental, foram conduzidos dois ensaios de digestibilidade. As médias, os coeficientes de variação $(C V)$ e de determinação $\left(r^{2}\right)$ e as equações de regressão ajustadas (ER) para os níveis de nutrientes digestíveis totais (NDT) das dietas e a digestibilidade aparente dos nutrientes, tendo as silagens pré-secas de capim-braquiária e capim-tifton como volumosos, encontram-se, respectivamente, nas Tabelas 5 e 6 . Todas as variáveis apresentaram comportamento semelhante, independentemente do tipo de volumoso utilizado, com exceção da DPB.

Os teores de NDT, a DMS e DMO apresentaram efeito linear em função do incremento nos níveis de concentrado nas rações, o qual contribuiu positivamente para a digestibilidade dos nutrientes, excetuando a fibra em detergente neutro (FDN). As DMS e DMO também mostraram efeito linear em função do aumento do nível de concentrado nas dietas. Os resultados de Cardoso et al. (2000) e Dias et al. (2000) corroboram os efeitos observados nesse trabalho. Por outro lado, Véras et al. (2000b), trabalhando com níveis de 12,5 a $75 \%$ de concentrado nas dietas, registraram comportamento quadrático para estas variáveis, com coeficientes de digestibilidade máximos estimados de 69,3 e 70,7, respectivamente, para MS e MO, com níveis de 56,4 e 56,7\% de concentrado na base da matéria seca da dieta.

Vários trabalhos discutem o efeito da relação volumoso:concentrado sobre os coeficientes de digestibilidade. Valadares Filho (1985), citado por Carvalho et al. (1997a,b), utilizando níveis de 40 e $60 \%$ de concentrado e feno de capim-gordura, observou coeficiente de digestibilidade de MS maior para o nível de $60 \%$ de concentrado, o que, segundo o autor, resultou da maior concentração de carboidratos não-estruturais, que, por apresentarem maior coeficiente de digestibilidade aparente, quando comparados aos carboidratos não-estruturais, influenciaram positivamente a digestibilidade da MS. Portanto, de forma semelhante, o aumento na concentração de carboidratos não-fibrosos frente à adição de concentrado pode ter influenciado positivamente as digestibilidades da MS e MO.

A digestibilidade da fração FDN diminuiu de forma linear com a adição de concentrados à ração. A adição de concentrado às dietas de ruminantes pode provocar redução na digestibilidade ruminal da fibra, em decorrência do aumento nas proporções dos carboidratos prontamente fermentáveis e da conseqüente redução do $\mathrm{pH}$ do ambiente ruminal, que pode reduzir sensivelmente a atividade das bactérias 
Tabela 5 - Médias, coeficientes de variação (CV) e de determinação $\left(r^{2}\right)$ e equações de regressão ajustadas (ER) para os níveis de nutrientes digestíveis totais (NDT) das dietas e digestibilidades aparentes da matéria seca (DMS), matéria orgânica (DMO), proteína bruta (DPB), extrato etéreo (DEE), fibra em detergente neutro (DFDN) e carboidratos não-fibrosos (DCNF), em função dos níveis de concentrado nas dietas (C) contendo silagem pré-seca de capim-braquiária como volumoso

Table 5 - Means, coefficients of variation (CV) and determination $\left(r^{2}\right)$ and fitted regression equations $(R E)$ for total digestible nutrients levels (TDN) and apparent digestibilities of dry matter $(D D M)$, organic matter (OMD), crude protein (CPD), ether extract (EED), neutral detergent fiber (NDFD), nonfiber carbohydrates (NFCD), according to the concentrate level in the diets (C), when Brachiariagrass was used as aroughage source

\begin{tabular}{|c|c|c|c|c|c|c|}
\hline \multirow[t]{2}{*}{$\begin{array}{l}\text { Itens } \\
\text { Items }\end{array}$} & \multicolumn{3}{|c|}{$\begin{array}{c}\text { Níveis de concentrado } \\
\text { (\% MS) } \\
\text { Dietary concentrate } \\
\text { levels }(\% \text { DM) }\end{array}$} & \multirow[t]{2}{*}{$\mathrm{CV}(\%)$} & \multirow[t]{2}{*}{$\mathrm{r}^{2}(\%)$} & \multirow[t]{2}{*}{$\mathrm{ER}(\mathrm{p}<0,05)$} \\
\hline & 5 & 35 & 65 & & & \\
\hline $\begin{array}{l}\text { NDT (\%MS) } \\
\text { TDN (\%DM) }\end{array}$ & 64,0 & 67,76 & 70,7 & 3,23 & 99,74 & $\hat{\mathrm{Y}}=63,5483+0,111167 \mathrm{C}$ \\
\hline $\begin{array}{l}\text { DMS } \\
D M D\end{array}$ & 64,2 & 68,06 & 69,0 & 3,92 & 89,10 & $\hat{\mathrm{Y}}=64,2985+0,0790417 \mathrm{C}$ \\
\hline $\begin{array}{l}\text { DMO } \\
O M D\end{array}$ & 65,3 & 70,2 & 71,1 & 3,66 & 86,66 & $\hat{\mathrm{Y}}=65,5002+0,0962083 \mathrm{C}$ \\
\hline $\begin{array}{l}\mathrm{DPB} \\
C P D\end{array}$ & 72,7 & 71,3 & 71,0 & 3,82 & - & $\hat{Y}=71,68$ \\
\hline $\begin{array}{l}\text { DEE } \\
E D D\end{array}$ & 57,3 & 68,9 & 71,8 & 6,21 & 98,92 & $\hat{\mathrm{Y}}=56,5183+0,241667 \mathrm{C}$ \\
\hline $\begin{array}{l}\text { DFDN } \\
N D F D\end{array}$ & 68,6 & 62,5 & 51,8 & 5,63 & 97,62 & $\hat{Y}=70,7148-0,279375 C$ \\
\hline $\begin{array}{l}\text { DCNF } \\
N F C D\end{array}$ & 53,0 & 86,6 & 87,9 & 4,32 & 77,83 & $\hat{\mathrm{Y}}=54,1504+0,606083 \mathrm{C}$ \\
\hline
\end{tabular}

Tabela 6 - Médias, coeficientes de variação $(C V)$ e de determinação $\left(r^{2}\right)$ e equações de regressão ajustadas (ER) para os níveis de nutrientes digestíveis totais (NDT) das dietas e digestibilidades aparentes da matéria seca (DMS), matéria orgânica (DMO), proteína bruta (DPB), extrato etéreo (DEE), fibra em detergente neutro (DFN) e carboidratos não-fibrosos (DCNF), em função dos níveis de concentrado nas dietas (C) contendo silagem pré-seca de capim-tifton como volumoso

Table 6 - Means, coefficients of variation (CV) and determination $\left(r^{2}\right)$ and fitted regression equations (RE) for the total digestible nutrients levels (TDN) and apparent digestibilities of dry matter $(D M D)$, organic matter $(O M D)$, crude protein $(C P D)$, ether extract (EED), neutral detergent fiber (NDFD), nonfiber carbohydrate (NFCD), according to the concentrate level in the diets (C), when tifton grass was used as a roughage source

\begin{tabular}{|c|c|c|c|c|c|c|}
\hline \multirow[t]{2}{*}{$\begin{array}{l}\text { Itens } \\
\text { Items }\end{array}$} & \multicolumn{3}{|c|}{$\begin{array}{c}\text { Níveis de concentrado } \\
(\% \mathrm{MS}) \\
\text { Dietary concentrate } \\
\text { levels }(\% \text { DM) }\end{array}$} & \multirow[t]{2}{*}{$\mathrm{CV}(\%)$} & \multirow[t]{2}{*}{$\mathrm{r}^{2}(\%)$} & \multirow[t]{2}{*}{$\mathrm{ER}(\mathrm{p}<0,05)$} \\
\hline & 5 & 35 & 65 & & & \\
\hline $\begin{array}{l}\text { NDT (\%MS) } \\
T D N(\% D M)\end{array}$ & 68,5 & 73,4 & 81,4 & 1,51 & 97,92 & $\hat{\mathrm{Y}}=66,9285+0,214542 \mathrm{C}$ \\
\hline $\begin{array}{l}\text { DMS } \\
D M D\end{array}$ & 69,3 & 74,6 & 81,3 & 1,85 & 99,56 & $\hat{\mathrm{Y}}=68,0144+0,201375 \mathrm{C}$ \\
\hline $\begin{array}{l}\mathrm{DMO} \\
O M D\end{array}$ & 70,7 & 76,0 & 82,6 & 1,65 & 99,68 & $\hat{\mathrm{Y}}=69,4565+0,198958 \mathrm{C}$ \\
\hline $\begin{array}{l}\mathrm{DPB} \\
C P D\end{array}$ & 74,6 & 75,5 & 80,8 & 1,44 & 86,20 & $\hat{\mathrm{Y}}=73,3398+0,103125 \mathrm{C}$ \\
\hline $\begin{array}{l}\mathrm{DEE} \\
E D D\end{array}$ & 57,4 & 72,9 & 83,6 & 7,3 & 98,9 & $\hat{\mathrm{Y}}=56,0477+0,436042 \mathrm{C}$ \\
\hline $\begin{array}{l}\text { DFDNN } \\
D F D\end{array}$ & 74,1 & 72,1 & 70,5 & 2,7 & 99,9 & $\hat{\mathrm{Y}}=74,314-0,0600417 \mathrm{C}$ \\
\hline $\begin{array}{l}\text { DCNF } \\
N F C D\end{array}$ & 68,1 & 88,1 & 94,6 & 3,3 & 92,0 & $\hat{\mathrm{Y}}=68,1542+0,442000 \mathrm{C}$ \\
\hline
\end{tabular}


fibrolíticas. Considerando esta premissa verdadeira, conclui-se que a queda na digestibilidade da fração FDN pode ser justificada pelo aumento de carboidratos prontamente fermentáveis.

As DEE e DCNF apresentaram efeito linear em função do incremento de concentrado, indicando que houve efeito associativo positivo da adição de concentrado sobre as digestibilidades destes nutrientes. Dias et al. (2000) e Ítavo et al. (2002) também verificaram comportamento semelhante para a DEE. Segundo Dias et al. (2000), o aumento na DEE pode ser explicado pela redução da contribuição das perdas endógenas quando se tem maior consumo deste nutriente.

A DPB verificada no primeiro ensaio de digestibilidade, quando os animais receberam a silagem pré-seca de capim-braquiária como volumoso, não foi alterada por maiores níveis de concentrado. Por outro lado, quando se utilizou a silagem pré-seca de capimtifton, observou-se crescimento linear da DPB. Ladeira et al. (1999) constataram efeito linear crescente do nível de concentrado sobre a DPB, diferindo de Ítavo et al. (2002), que não encontraram efeito da adição de concentrado na dieta sobre esta variável.

Constam, na Tabela 7, as médias, os coeficientes de variação $(\mathrm{CV})$ e de determinação $\left(\mathrm{r}^{2}\right)$ e as equações de regressão ajustadas (ER) para os ganhos médios diários de peso vivo (GMDPV), de peso de corpo vazio (GMDPVZ) e de carcaça (GMDCAR), em função dos níveis de concentrado nas dietas. Os GMDPV, GMDPVZ e GMDCAR elevaram linearmente em função da adição de concentrado às dietas. Os pesos vivos médios de abate dos animais correspondentes aos tratamentos com 5, 35 e $65 \%$ de concentrado foram de 340, 361 e 375, respectivamente.

Souza et al. (2002) e Bren et al. (2002), também verificaram melhor desempenho dos animais com o incremento dos níveis de concentrado nas rações, que proporcionou aumento do consumo e digestibilidade da matéria seca.

As médias e equações de regressão, com seus respectivos coeficientes de variação e de determinação para os rendimentos de carcaça e dos cortes básicos da carcaça, comprimento de carcaça (CCAR), área de olho de lombo (AOL) e espessura de gordura subcutânea (EG), em função dos níveis de concentrado da dieta, são apresentados na Tabela 8. O rendimento de carcaça, nas duas formas de expressão, não foi afetado pela adição de concentrados à dieta. Os rendimentos de carcaça, expressos em relação ao peso vivo e em relação ao peso de corpo vazio, apresentaram valores médios respectivos de 56,3 e $62,8 \%$, que foram bem próximos aos obtidos por Silva et al. (2002 a,b), que também não verificaram efeito do nível de concentrado sobre os rendimentos de carcaça de bovinos Nelore na fase de recria, obtendo valores médios de 57,4 e 64,3\%, respectivamente, para os rendimentos em relação ao peso vivo e ao peso de corpo vazio.

O CCAR não foi afetado pelo incremento de concentrado, entretanto, a AOL e a EG elevaram linearmente em função do acréscimo de concentrado. $\mathrm{O}$ aumento da AOL pode ter sido reflexo do maior

Tabela 7 - Médias, coeficientes de variação (CV) e de determinação $\left(r^{2}\right)$ e equações de regressão ajustadas (ER) para os ganhos médios diários de peso vivo (GMDPV), peso de corpo vazio (GMDPVZ) e de carcaça (GMDCAR), em função dos níveis de concentrado nas dietas $(C)$

Table 7 - Means, coefficients of variation (CV) and determination $\left(r^{2}\right)$ and fitted regression equations (RE) for the average daily live weight (LWG), empty body weight (EBWG) and carcass (CG) gains, in function of the concentrate levels in the diets (C)

\begin{tabular}{|c|c|c|c|c|c|c|}
\hline \multirow[t]{2}{*}{$\begin{array}{l}\text { Itens } \\
\text { Items }\end{array}$} & \multicolumn{3}{|c|}{$\begin{array}{c}\text { Níveis de concentrado } \\
\text { na dieta }(\% \mathrm{MS}) \\
\text { Dietary concentrate } \\
\text { levels }(\% \text { DM) }\end{array}$} & \multirow[t]{2}{*}{$\mathrm{CV}(\%)$} & \multirow[t]{2}{*}{$\mathrm{r}^{2}(\%)$} & \multirow[t]{2}{*}{$\mathrm{ER}(\mathrm{p}<0,05)$} \\
\hline & 5 & 35 & 65 & & & \\
\hline $\begin{array}{l}\text { GMDPV }(\mathrm{kg}) \\
L W G(k g)\end{array}$ & 0,67 & 0,90 & 1,07 & 21,6 & 99,25 & $\hat{Y}=0,641667+0,0066667 \mathrm{C}$ \\
\hline $\begin{array}{l}\text { GMDPVZ }(\mathrm{kg}) \\
E B W G(k g)\end{array}$ & 0,53 & 0,85 & 1,00 & 15,7 & 95,82 & $\hat{\mathrm{Y}}=0,516667+0,0078333 \mathrm{C}$ \\
\hline $\begin{array}{l}\text { GMDCAR }(\mathrm{kg}) \\
C G(k g)\end{array}$ & 0,33 & 0,55 & 0,62 & 17,1 & 90,67 & $\hat{\mathrm{Y}}=0,327708+0,004875 \mathrm{C}$ \\
\hline
\end{tabular}


Tabela 8 - Médias, equações de regressão (ER), coeficientes de variação (CV) e de determinação $\left(r^{2}\right)$ para os rendimentos de carcaça em relação ao peso vivo (RCPV) e ao peso de corpo vazio (RCPVZ); rendimentos de dianteiro (RD), paleta (RPAL), acém (RAC), traseiro completo (RT), ponta de agulha (RPA), alcatra completa (RALC) e coxão (RCOX); comprimento de carcaça (CCAR); área de olho de lombo (AOL) e espessura de gordura subcutânea (EG), em função dos níveis de concentrado nas dietas $(\mathrm{C})$

Table 8 - Means, coefficients of variation (CV) and determination $\left(r^{2}\right)$ and fitted regression equations (RE) for the carcass dressing percentage as a function of live weight (DPLW) and empty body weight (DPEBW); percentage of forequarter, arm, nech, brischet and chuck, hindquarter, spare rib, surloin and leg; carcass length $(C L)$; loin eye area (LEA) and subcutaneous fat thickness (SFT), according to the dietary concentrate levels (C)

\begin{tabular}{|c|c|c|c|c|c|c|}
\hline \multirow[t]{2}{*}{$\begin{array}{l}\text { Itens } \\
\text { Items }\end{array}$} & \multicolumn{3}{|c|}{$\begin{array}{l}\text { Níveis de concentrado } \\
(\% \mathrm{MS}) \\
\text { ary concentrate levels (\% DM) }\end{array}$} & \multirow[t]{2}{*}{$\mathrm{CV}(\%)$} & \multirow[t]{2}{*}{$\mathrm{r}^{2}(\%)$} & \multirow[t]{2}{*}{$\mathrm{ER}(\mathrm{p}<0,05)$} \\
\hline & 5 & 35 & 65 & & & \\
\hline RCPV (\%) & 54,5 & 57,4 & 57,0 & 2,7 & - & $\hat{Y}=56,27$ \\
\hline $\begin{array}{l}\operatorname{RCPVZ}(\%) \\
D P E B W(\%)\end{array}$ & 62,5 & 63,2 & 62,8 & 1,1 & - & $\hat{Y}=62,83$ \\
\hline $\begin{array}{l}\mathrm{RD}(\%) \\
\text { Forequarter (\%) }\end{array}$ & 38,7 & 38,4 & 39,5 & 1,9 & - & $\hat{\mathrm{Y}}=38,87$ \\
\hline $\begin{array}{l}\text { RPAL }(\%) \\
\operatorname{Arm}(\%)\end{array}$ & 18,6 & 19,2 & 18,4 & 4,5 & - & $\hat{\mathrm{Y}}=18,74$ \\
\hline $\begin{array}{l}\mathrm{RAC}(\%) \\
\text { Nech, brischet and } \\
\text { chuck }(\%)\end{array}$ & 20,1 & 19,2 & 21,1 & 4,5 & - & $\hat{\mathrm{Y}}=20,14$ \\
\hline $\begin{array}{l}\text { RT (\%) } \\
\text { Hindquarter }(\%)\end{array}$ & 61,3 & 61,6 & 60,5 & 1,2 & - & $\hat{Y}=61,13$ \\
\hline $\begin{array}{l}\text { RPA }(\%) \\
\text { Spare rib }(\%)\end{array}$ & 12,3 & 13,5 & 13,1 & 9,7 & - & $\hat{Y}=12,96$ \\
\hline $\begin{array}{l}\text { RALC }(\%) \\
\text { Surloin }(\%)\end{array}$ & 19,3 & 19,0 & 19,8 & 2,5 & - & $\hat{Y}=19,37$ \\
\hline $\begin{array}{l}\operatorname{RCOX}(\%) \\
\operatorname{Leg}(\%)\end{array}$ & 29,7 & 29,1 & 27,5 & 3,8 & 94,48 & $\hat{Y}=30,039-0,0355417 \mathrm{C}$ \\
\hline $\begin{array}{l}\text { CCAR }(\mathrm{m}) \\
C L(m)\end{array}$ & 1. & 1.1 & 1.1 & 2,9 & - & $\hat{Y}=1,08$ \\
\hline $\begin{array}{l}\operatorname{AOL}\left(\mathrm{cm}^{2}\right) \\
\operatorname{LEA}\left(\mathrm{cm}^{2}\right)\end{array}$ & 48,4 & 53,8 & 54,6 & 6,5 & 84,57 & $\hat{\mathrm{Y}}=48,6185+0,103708 \mathrm{C}$ \\
\hline $\begin{array}{l}\mathrm{EG}(\mathrm{mm}) \\
\operatorname{SFT}(\mathrm{mm})\end{array}$ & 2,54 & 3,3 & 4,9 & 30,6 & 96,43 & $\hat{\mathrm{Y}}=2,16667+0,04 \mathrm{C}$ \\
\hline
\end{tabular}

desenvolvimento dos animais submetidos a maiores níveis de concentrado na dieta. Animais alimentados com rações contendo maiores níveis energéticos tendem a depositar maior quantidade de gordura, quando comparados a animais recebendo dietas com menores níveis de energia, podendo explicar a maior deposição de gordura subcutânea daqueles que receberam maiores níveis de concentrado.

O grau de terminação das carcaças, avaliado pela espessura da gordura subcutânea (EG), pode ser considerado adequado independentemente do tratamento, uma vez que o sistema BRASIL de tipificação de carcaças permite que carcaças com gordura escassa (1 a 3 mm de gordura subcutânea) sejam consideradas adequadas (Cruz, 2000). Entre- tanto, segundo Luchiari Filho (2000), para ser considerada de boa qualidade, uma carcaça deve possuir espessura mínima de gordura de $3 \mathrm{~mm}$.

Não foi verificado efeito dos níveis de concentrado sobre o rendimento dos cortes estudados, com exceção do RCOX, que decresceu linearmente em função do incremento de concentrado. Os RPAL, RAC, RPA e RALC médios foram de 18,7; 20,1; 13,0 e 19,4\%, respectivamente. As médias para os rendimentos dianteiro e traseiro foram respectivamente, 38,9 e 61,19\%, semelhantes às encontradas por Silva et al.(2002 a,b), de 39,39 e 60,7 para os rendimentos dianteiro e traseiro, respectivamente. Esses autores também não encontraram efeito dos diferentes níveis de concentrado sobre os rendimentos dos demais cortes. 


\section{Conclusões}

A elevação do nível de concentrado até $65 \%$ da MS promoveu melhor digestibilidade da dieta e maior desempenho dos animais.

Características da carcaça, como área de olho de lombo e espessura de gordura subcutânea, podem ser alteradas via manipulação do nível de concentrado nas dietas.

\section{Literatura Citada}

BREN, L; ROSSI JR., P.; MOLETTA, J.L. et al. Desempenho em confinamento de novilhos de corte alimentados com diferentes níveis de concentrado na dieta. In: REUNIÃO ANUAL DA SOCIEDADE BRASILEIRA DE ZOOTECNIA, 39., 2002, Recife. Anais... Recife: CD-ROM. Nutrição de Ruminantes. Resumo 838.

CARDOSO, R.C.; VALADARES FILHO, S.C.; COELHO da SILVA, J. F. et al. Consumo e digestibilidades aparentes totais e parciais de rações contendo diferentes níveis de concentrado, em novilhos F1 Limousin x Nelore. Revista Brasileira de Zootecnia, v.29, n.6, p.1832-1841, 2000.

CARVALHO, A.U.; VALADARES FILHO, S.C.; COELHO DA SILVA, J.F. et al. Níveis de concentrado em dietas de zebuínos. 1- Consumo e digestibilidade aparente. Revista Brasileira de Zootecnia, v.26, n.5, p.986-995, 1997a.

CARVALHO, A.U; VALADARES FILHO, S.C.; COELHO DA SILVA, J.F. et al. Níveis de concentrado em dietas de zebuínos. 3- Eficiência microbiana e população de protozoários ruminais. Revista Brasileira de Zootecnia, v.26, n.5, p.1007-1015, 1997 b.

COCHRAN, R.C.; ADAMS, D.C.; WALLACE, J.D. et al. Predicting digestibilidty diets with internal markers: Evaluation of four potential markers. Journal of Animal Science, v.63, p.1476-1483, 1986.

COELHO DA SILVA, J.F.; LEÃO, M.I. Fundamentos de nutrição dos ruminantes. Piracicaba: Livroceres, 1979. 380p.

CRUZ, G.M. Produção de carne bovina utilizando confinamento. In: SIMPÓSIO SOBRE MANEJO E NUTRIÇÃO DE GADO DE CORTE, 2000, Goiânia. Anais... Goiânia: 2000. p.91.

DIAS, H.L.C.; VALADARES FILHO, S.C.; COELHODA SILVA, J.F. et al. Consumo e digestões totais e parciais em novilhos F1 Limousin x Nelore alimentados com dietas contendo cinco níveis de concentrado. Revista Brasileira de Zootecnia, v.29, n.2, p.545-554, 2000.

EUCLIDES FILHO, K.; EUCLIDES, V.P.B.; FIGUEIREDO, G.R. et al. Avaliação de animais nelores e seus mestiços com Charolês, Fleckvieh e Chianina, em três dietas. 1. Ganho de peso e conversão alimentar. Revista Brasileira de Zootecnia, v.26, n.1, p.66-72, 1997.

FEIJÓ, G.D.; SILVA, J.M.; THIAGO, L.R.L.S. et al. Efeito de níveis de concentrado na engorda de bovinos confinados. Desempenho de novilhos Nelore. In: REUNIÃO ANUAL DA SOCIEDADE BRASILEIRA DE ZOOTECNIA, 33., 1996, Fortaleza. Anais... Fortaleza: Sociedade Brasileira de Zootecnia, 1996a. p.70.
GESUALDI JR., A.; PAULINO, M.F.; VALADARES FILHO, S.C. et al. Níveis de concentrado na dieta de novilhos F1 Limousin x Nelore: consumo, conversão alimentar e ganho de peso. Revista Brasileira de Zootecnia, v.29, n.5, p.14581466, 2000a.

HALL, M.B. Calculation of non-structural carbohydrate content of feeds that contain non-protein nitrogen. Florida: University of Florida, 2000. p. A-25 (Bulletin 339).

ÍTAVO, L.C.V.; VALADARES FILHO, S.C.; SILVA, F.F. et al. Níveis de concentrado e proteína bruta na dieta de bovinos Nelore nas fases de recria e terminação: Consumo e digestibilidade. Revista Brasileira de Zootecnia, v.31, n.2, p.1033-1041, 2002.

LADEIRA, M.M.; VALADARES FILHO, S.C.; SILVA, J.F.C. et al. Consumo e digestibilidades aparentes totais e parciais de dietas contendo diferentes níveis de concentrado, em novilhos Nelore. Revista Brasileira de Zootecnia, v.28, n.2, p.395-403, 1999.

LUCHIARI FILHO, A. Pecuária da carne bovina. 1.ed. São Paulo: A. Luchiari Filho, 2000. 134p.

MERTENS, D.R. Regulation of forage intake. In: FAHEY Jr., G.C., (Ed.) Forage quality, evaluation and utilization. Madison: American Society of Agronomy,1994. p.450-493.

MOLETTA, J.L.; RESTLE, J. Características de carcaças de novilhos de diferentes grupos genéticos terminados em confinamento. Revista da Sociedade Brasileira de Zootecnia, v.25, n.5, p.876-888, 1996.

PAULINO, P.V.R.; COSTA, M.A.I..; VALADARES FILHO, S.C. et al. Exigências nutricionais de zebuínos: proteína. Revista Brasileira de Zootecnia, v.33, n.3, p.759-769, 2004a.

PAULINO, P.V.R.; COSTA,M.A.I.; VALADARES FILHO, S.C. et al. Exigências nutricionais de zebuínos: minerais. Revista Brasileira de Zootecnia, v.33, n.3, p.770-780, 2004b.

PAULINO, P.V.R.; COSTA,M.A.I..; VALADARES FILHO, S.C. et al. Exigências nutricionais de zebuínos: energia. Revista Brasileira de Zootecnia, v.33, n.3, p.781-791, 2004c.

SILVA, D.J.; QUEIROZ, A C. Análise de alimentos (métodos químicos e biológicos). 3.ed. Viçosa, MG: Universidade Federal de Viçosa, 2002. 235p.

SILVA, F.F.; VALADARES FILHO, S.C.; ÍTAVO, L.C.V. et al. Desempenho produtivo de novilhos Nelore, na recria e na engorda, recebendo dietas com diferentes níveis de concentrado e proteína. Revista Brasileira de Zootecnia, v.31, n.1 (suplemento), p.492-502, 2002a.

SILVA, F.F.; VALADARES FILHO, S.C.; ÍTAVO, L.C.V. et al. Composição corporal e requisitos energéticos e protéicos de bovinos Nelore, não-castrados, alimentados com rações contendo diferentes níveis de concentrado e proteína. Revista Brasileira de Zootecnia, v.31, n.1, p.503-513, 2002b. (suplemento)

SOUZA, V.G.; PEREIRA, O.G.; VALADARES FILHO, S.C. et al. Consumo e desempenho de bovinos de corte recebendo dietas contendo silagem de milho e concentrado em diferentes proporções. In: REUNIÃO ANUAL DA SOCIEDADE BRASILEIRA DE ZOOTECNIA, 39., 2002, Recife. Anais... Recife: SBZ, 2002. CD-ROM. Nutrição de Ruminantes. Resumo 659.

STRACK, A.G.; MOLETTA, J.L.; PEROTTO, D. et al. Efeito dos níveis de concentrado, sobre características de carcaça de novilhos terminados em confinamento. In: REUNIÃO ANUAL DA SOCIEDADE BRASILEIREA DE ZOOTECNIA, 38., 2001, Piracicaba. Anais... Piracicaba: Sociedade Brasileira de Zootecnia, 2001. p.1239. 
UNIVERSIDADE FEDERAL DE VIÇOSA - UFV. SAEG Sistema de análises estatísticas e genéticas. Versão 7.1. Viçosa, MG: 1997. 150p. (Manual do usuário)

Van SOEST, P.J. Nutritional ecology of the ruminant. 2.ed. London: Comstock Publishing Associates, 1994. 476p.

VÉRAS, A.S.C.; VALADARES FILHO, S.C.; SILVA, J.F.C. et al. Níveis de concentrado na dieta de animais nelore não castrados: I. Consumo. In: REUNIÃO ANUAL DA SOCIEDADE BRASILEIRA DE ZOOTECNIA, 37., 2000, Viçosa, MG. Anais... Viçosa, MG: Sociedade Brasileira de Zootecnia, 2000a. CD-ROM. Nutrição de ruminantes. Pôster 1073.

VÉRAS, A.S.C.; VALADARES FILHO, S.C.; SILVA, J.F.C. et al. Níveis de concentrado na dieta de animais nelore não castrados. II. Digestibilidade aparente. In: REUNIÃO ANUAL DA SOCIEDADE BRASILEIRA DE ZOOTECNIA, 37., 2000, Viçosa, MG. Anais... Viçosa, MG: Sociedade Brasileira de Zootecnia, 2000b. CD-ROM. Nutrição de ruminantes. Pôster 1107.
WEISS, W.P. Energy prediction equations for ruminant feeds. In: CORNELL NUTRITION CONFERENCE FOR FEED MANUFACTURERS, 61., 1999, Ithaca. Proceedings... Ithaca: Cornell University, 1999. p.176-185.

Recebido em: 13/01/03

Aceito em: 28/12/04 